\title{
New and simple plate test for screening relative transfructosylation activity of fungi
}

\author{
Ana Dominguez ${ }^{1}$, Isabel M. Santos ${ }^{1,2}$, José A. Teixeira ${ }^{1}$ and Nelson Lima ${ }^{1,2}$ \\ ${ }^{\prime}$ Centro de Engenharia Biológica and ${ }^{2}$ Micoteca da Universidade do Minho, Universidade do Minho, Braga, Portugal \\ Summary Several microorganisms are reported to have transfructosylation activity due to \\ fructosyltransferase and/or fructofuranosidase activities. However, the search \\ for other fungi with higher transfructosylation activity remains a challenge. \\ So, a presumptive and indirect colorimetric plate assay for the evaluation of \\ transfructosylation activity in fungi was developed which involved the \\ simultaneous determination in the same plate of glucose and fructose released \\ from sucrose. The method entailed the (a) glucose oxidase-peroxidase coupled \\ reaction using phenol and 4-aminoantipyrine for determination of glucose; \\ and (b) fructose dehydrogenase oxidation in the presence of a tetrazolium salt \\ for determination of fructose. The presence of enzymes with transfructosylation \\ activity was identified by the formation of pink (presence of glucose) and blue \\ (presence of fructose) halos around the fungal colony. In conclusion, the results \\ showed that the method is suitable for screening a large number of fungi due to \\ its simplicity, reproducibility and rapidity and also gives a relative quantitative \\ estimation of the transfructosylation activity of different fungi species.
}

Key words Transfructosylation, Fructosyltransferase, Fructofuranosidase, Fructose, Glucose

Fructooligosaccharides (FOS) have received particular attention recently because of their excellent biological and functional properties as prebiotic compounds. FOS stimulates the growth and activity of intestinal microflora and are non-digestible, calorie-free and non-carcinogenic sweeteners. They are considered to have many health benefits such as immune system activation, resistance to infections, synthesis of B-complex vitamins, calcium absorption and decrease of total cholesterol and lipid in blood serum. They can also be used to treat breast cancer, diarrhea, and constipation. FOS are found in trace amounts in foods such as onions, Jerusalem artichokes, asparagus, wheat, rye, garlic, tomatoes, bananas and honey. However, mass production is limited by seasonal restrictions and the inherent inefficiencies of these natural systems $[6,7,9,10]$.

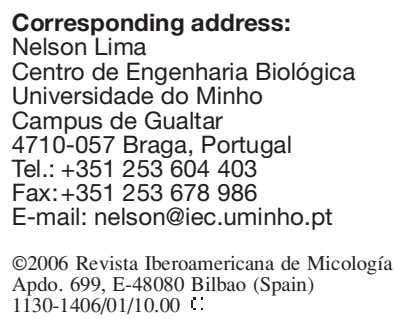

FOS are fructose oligomers with a terminal glucose group, in which 2-4 fructosyl moieties are linked via $\beta(1$ 2)-glycosidic bonds. Their structural formula is (1)-D-glucopyranosyl-(1 2)-B-D-fructofuranosyl-(1;2)-]n $(\mathrm{GF} n)$ and they are mainly composed of 1-kestose (GF2), nystose (GF3) and $1^{\mathrm{F}}$-fructofuranosyl-nystose (GF4) $[4,12]$. They are produced by the action of two enzymes with transfructosylation activity. These enzymes are invertase, ( $($-fructofuranosidase fructohydrolase, FFase, EC 3.2.1.26) and sucrase (sucrose fructosyl transferase, FTase, EC 2.4.1.9) [2].

Glucose and fructose are reaction products associated with the synthesis of FOS and usually the transfructosylation activity of FFase and FTase is estimated by separate assay of glucose and fructose and determination of the excess of glucose produced over fructose [3]. The detection of glucose is based on the well known glucose oxidase (GOD) - peroxidase (POD) system $[1,8]$. The principle of this test is:

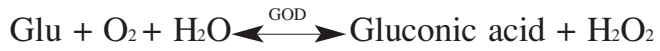

$\mathrm{H}_{2} \mathrm{O}_{2}+4$ - aminoantipyrine + phenol $\stackrel{\mathrm{POD}}{\longrightarrow}$ chromogen (pink)

For the determination of fructose, fructose dehydrogenase $(\mathrm{FDH})$ is employed, as shown in the following reaction [5]:

$$
\begin{gathered}
\text { Fruc }+ \text { MMT }+ \text { Phenazine methosulfate } \stackrel{\text { FDH }}{\longrightarrow}-5-\text { Keto }- \\
\text { D - fruc }+ \text { chromogen (blue) }
\end{gathered}
$$

This work reports the development of a presumptive and indirect colorimetric plate assay for screening relative transfructosylation activity of fungi by the simultaneous determination of glucose and fructose in the same sample. 


\section{Materials and methods}

Reagents and enzymes. MTT (Methylthiazolyldiphenyl-tetrazolium bromide) was obtained from Sigma (USA), phenol and 4-aminoantipyrine were from Fluka (Germany) and phenazine methosulfate from Acros (Portugal). Fructose dehydrogenase (FDH) from Gluconobacter sp. was purchased from Toyobo (Japan) and glucose oxidase from Aspergillus niger (GOD) and horseradish peroxidase (POD) were from Fluka. Agar technical n. ${ }^{\circ} 3$ and Czapek Dox Media (CD) were obtained from Oxoid (UK). Reagents preparation. Citric phosphate buffer (CPB) at $\mathrm{pH} 5$ was used to prepare all stock solutions. Stock solutions of MTT and 4-aminoantipyrine were prepared at $10 \mathrm{mg} / \mathrm{ml}$ and stored at $4{ }^{\circ} \mathrm{C}$. A solution of phenol at $20 \mathrm{mg} / \mathrm{ml}$ was prepared and stored at $4{ }^{\circ} \mathrm{C}$. Phenazine methosulfate was prepared at a concentration of $0.1 \mathrm{~g} / \mathrm{ml}$ just prior to use. FDH and POD were also prepared at concentrations of $250 \mathrm{U} / \mathrm{ml}$ and $125 \mathrm{U} / \mathrm{mL}$, respectively. These stocks were stored at $-20{ }^{\circ} \mathrm{C}$. GOD was stored at $4{ }^{\circ} \mathrm{C}$, at a concentration of $1060 \mathrm{U} / \mathrm{ml}$. Under these conditions, both reagents and enzymes were stable.

Microorganisms and culture conditions. Aureobasidium pullulans CCY 27-1-94 (Culture Collection of Yeasts, Bratislava, Slovakia) was used as standard microorganism, since it has transfructosylation activity [11]. Aspergillus sp. strains (MUM 03.49, MUM 03.50, MUM 03.51, MUM 04.68, MUM 04.86, MUM 05.14, MUM 05.15, MUM 05.16) from Micoteca da Universidade do Minho (MUM, Braga, Portugal) were used as test microorganisms. The fungi were grown in $\mathrm{CD}$ plates at $25^{\circ} \mathrm{C}$ for five to seven days.

Screening procedure. One disc of mycelium ( $8 \mathrm{~mm}$ diameter) was cut from the edge of the colony of A. pullullans and placed onto CD agar plates and incubated at $25^{\circ} \mathrm{C}$ for $72 \mathrm{~h}$.

After incubation, the colony was overlaid with soft $\operatorname{agar}(0.7 \%(\mathrm{w} / \mathrm{v}))$ at $40{ }^{\circ} \mathrm{C}$ containing the biochemical reactive system, composed of: MTT $(0.2 \mathrm{mg} / \mathrm{ml})$, phenazine methosulfate $(2.5 \mathrm{mg} / \mathrm{l})$, 4-aminoantipyrine $(0.16 \mathrm{mg} / \mathrm{ml})$, phenol $(1 \mathrm{mg} / \mathrm{ml})$, FDH $(2 \mathrm{U} / \mathrm{ml})$, GOD $(9 \mathrm{U} / \mathrm{ml})$ and POD $(1 \mathrm{U} / \mathrm{ml})$ in CPB. After $10 \mathrm{~min}$, the results were analysed considering that the formation of pink (glucose) and blue (fructose) halos around the disc indicates the presence of the enzyme(s).

\section{Results and discussion}

Three CD agar plates with A. pullulans were overlaid with glucose and fructose dye systems, separately and combined, to demonstrate the advantages of coupling the two dye systems (Figure 1).

It can be seen in figure 1 that the dye system for detection of glucose reacts over all the plate while the system to detect fructose only reacts around the colony. For this reason, the background of the plate with the coupling of the two dye systems becomes darker, as a result of the overlapping of colours. However, the pink and blue halos around the colony remain indicating the presence of enzymes with transfructosylation activity.

The combined plate test was applied to Aspergillus spp. (Figure 2 and table 1). The results analysis was made considering that $A$. pullulans is the standard microorganism and exhibits a clearly positive reaction all over the plate (Figure 1f).
In figure 2 the differences between the colours of the plates are visible, indicating the different levels of transfructosylation activity of the Aspergillus strains. These results were semi-quantified using an empirical numerical scale according to table 1 . Thus, this method can give a relative quantitative estimation of the transfructosylation activity in fungi.

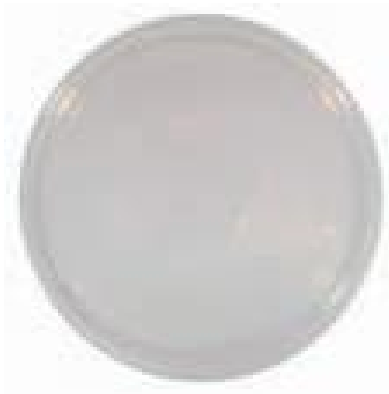

a
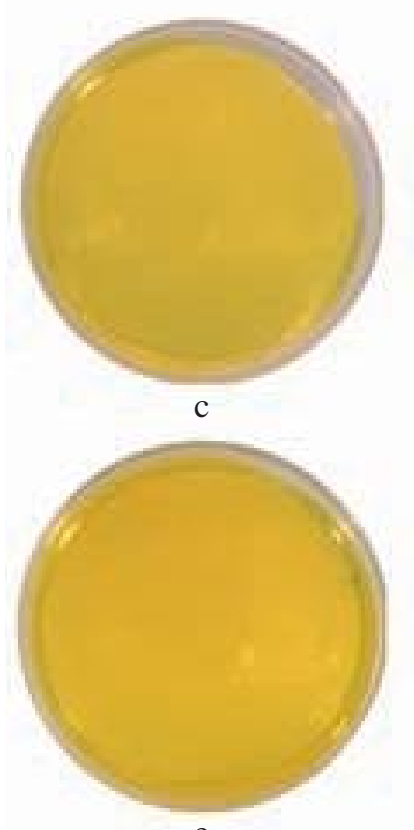

e

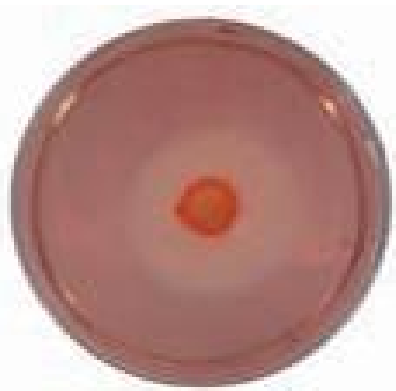

$\mathrm{b}$
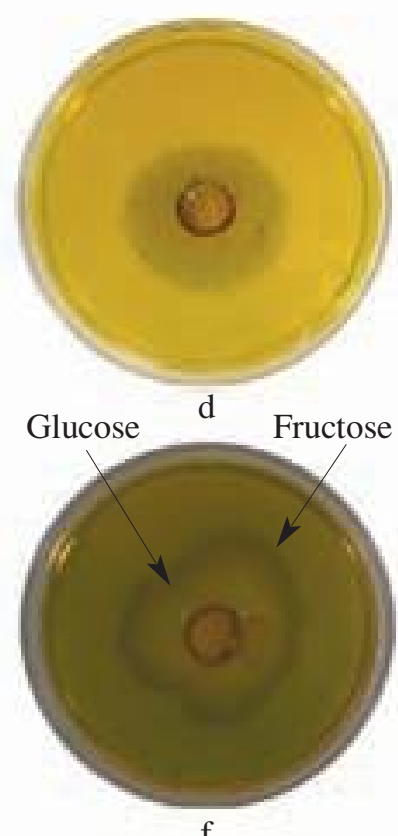

f
Figure 1. Detection of glucose (b), fructose (d) and glucose and fructose (f) in Aureobasidium pullullans colonies grown in CD plates. Plates $\mathrm{a}, \mathrm{c}$ and $\mathrm{e}$ are the negative controls for each dye system.

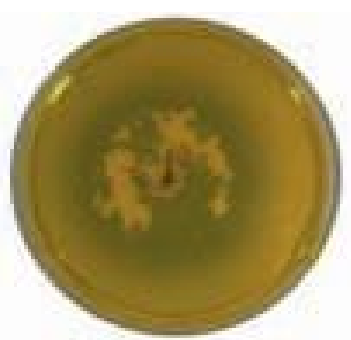

a

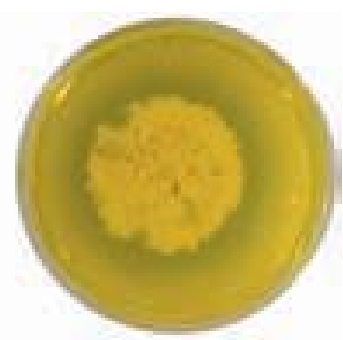

b
Figure 2. Screening results of relative transfructosylation activity in Aspergillus sp. MUM 03.49 (a) and Aspergillus sp. MUM 05.14 (b). 
Table 1. Screening results of relative transfructosylation activity in Aspergillus spp.

\begin{tabular}{lc}
\hline Microorganism & Result \\
\hline Aspergillus sp. MUM 03.49 & 2 \\
Aspergillus sp. MUM 03.50 & 2 \\
Aspergillus sp. MUM 03.51 & 2 \\
Aspergillus sp. MUM 04.68 & 2 \\
Aspergillus sp. MUM 04.86 & 2 \\
Aspergillus niger MUM 05.14 & 1 \\
Aspergillus niger MUM 05.15 & 1 \\
Aspergillus niger MUM 05.16 & 1 \\
\hline
\end{tabular}

0 - dye system does not react; 1 - dye system reacts in the border of the

colony; 2 - dye system reacts beyond the border of the colony; 3 - dye system reacts all over the plate (cf. Figure 1f)

\section{Conclusions}

The coupling of the two dye systems proved to be suitable for screening a large number of fungi due to its simplicity, reproducibility and rapidity. This method also gave an estimation of the transfructosylation activity of different fungi.
This work was supported by Agência de Inovação (AdI), Portugal, project BIOLIFE ref. PRIME 03/347.

A. Dominguez was supported by grant

SFRH/BD/23083/2005 from the Fundação para a

Ciência e Tecnologia (FCT), Portugal.

\section{References}

1. Barreto ES, Silva DO, Passos FML. A pratical method for screening for B-galactosidase secreting microbial colonies. Braz J Microbiol 2000; 31: 37-38.

2. Brenda - The Comprehensive Enzyme Information System. Cologne University Biolnformatics Center.

http://www.brenda.uni-koeln.de/. 3-5-2005.

3. Cairns AJ. Colorimetric microtiter plate assay of glucose and fructose by enzyme linked formazan production: applicability to the measurement of fructosyl transferase activity in higher plants. Anal Biochem 1987; 167: 270-278.

4. Ghazi I, Segura AGD, Fernández-Arrojo L, Alcalde M, Yates M, Rojas-Cervantes ML, Plou FJ, Ballesteros A. Immobilisation of fructosyltransferase from Aspergillus aculeatus on epoxy-activated Sepabeads EC for the synthesis of fructo-oligosaccharides. J Mol Catal 2005; 35: 19-27.
5. Holmes EW. Coupled enzymatic assay for the determination of sucrose. Anal Biochem 1997; 244: 103-109.

6. L'Hocine L, Wang Z, Jiang B, Xu S Purification and partial characterization of fructosyltransferase and invertase from Asuctosyltransferase and invertase from Aspergillus niger

7. Nguyen QD, Rezessy-Szabó JM, Bhat MK, Hoschke A. Purification and some properties of $B$-fructofuranosidase from Aspergillus niger IMI303386. Proc Biochem 2005; 40: 2461-2466.

8. Petzelbauer I, Nidetzky B, Haltrich D, Kulbe KD. Development of an ultra-high-temperature process for the enzymatic hydrolysis of lactose. 1 . The properties of two thermostable B-glycosidases. Biotechnol Bioeng 1999; 64: 322-332.
9. Sangeetha PT, Ramesh MN, Prapulla SG Maximization of fructooligosaccharide production by two stage continuous process and its scale up. J Food Eng 2005; 68: 57-64.

10. Tanriseven A, Aslan Y. Immobilization of Pectinex Ultra SP-L to produce fructooligosaccharides. Enzyme Microb Technol 2005; 36: 550-554.

11. Vandáková $M$, Platková Z, Antosová M Báles V, Polakovic M. Optimization of cultivation conditions for production of fructosyltransferase by Aureobasidium pullulans. Chem Pap 2004; 58:15-22.

12. Yun JW. Fructooligosaccharides Occurrence, preparation and application. Enzyme Microb Technol 1996; 19: 107-117. 